\title{
O uso das tecnologias digitais no ensinar matemática: recursos, percepções e desafios
}

\author{
El uso de las tecnologías digitales en enseñar matemáticas: recursos, \\ percepciones y desafios
}

\section{The use of digital technologies in teaching mathematics: resources, perceptions and challenges}

\begin{abstract}
Resumo
Com o avanço da tecnologia digital, algumas instituições de ensino como escolas e universidades tem repensado seus valores e práticas de ensino. Utilizou-se de um recorte de pesquisa realizado com estudantes da Universidade Federal do Rio Grande - FURG, curso de Licenciatura em Matemática, matriculados na disciplina de Tecnologias Aplicada à Educação Matemática I. Durante a disciplina uma das atividades os discentes conversaram com doze professores de escolas públicas, sobre o seu fazer pedagógico e a presença das tecnologias digitais nos espaços de atuação e produziram relatórios, com o objetivo de compreender o fazer pedagógico dos professores de Matemática da Educação Básica atrelado ao uso das tecnologias digitais. A partir dos registros gerados para análise utilizou-se a Análise Textual Discursiva (ATD) a fim de compreender o fenômeno investigado através dos discursos produzidos. Neste estudo, discutiu-se três categorias que emergiram da ATD: recursos utilizados pelos docentes, percepções sobre o uso das tecnologias digitais(TD) e desafios no ensinar matemática. A partir dessas três categorias, percebeu-se que os principais recursos utilizados pelos docentes entrevistados tem sido o livro didático e a internet para pesquisa de conceitos. Dentre as principais percepções e desafios está a formação continuada voltada para o uso das tecnologias digitais. No entanto, se faz necessário, repensar os recursos utilizados em sala de aula, bem como criar alternativas que atendam as necessidades dos sujeitos envolvidos e imersos em uma cultura tecnológica e assim contribuir para mudanças significativas no fazer docente no cenário atual.
\end{abstract}

Palavras-Chave: Tecnologias Digitais; Ensinar Matemática; Percepções; Desafios.

\section{Resumen}

Con el avance de la tecnología digital, algunas instituciones de enseñanza como escuelas y universidades han repensado sus valores y prácticas de enseñanza. Se utilizó un recorte de investigación realizado con estudiantes de la Universidad Federal de Rio Grande - FURG, curso de Licenciatura en Matemáticas, matriculados en la disciplina de Tecnologías Aplicada a la Educación Matemática I. Durante la disciplina una de las actividades los discentes conversaron con doce profesores de enseñanza las escuelas públicas, sobre su hacer pedagógico y la presencia de las tecnologías digitales en los espacios de actuación y produjeron informes, con el objetivo de comprender el hacer pedagógico de los profesores de Matemáticas de la Educación Básica ligado al uso de las tecnologías digitales. A partir de los registros generados para análisis se utilizó el Análisis textual Discursivo (ATD) a fin de comprender el fenómeno investigado a través de los discursos producidos. En este estudio, se discutieron tres categorías que emergieron de la ATD: recursos utilizados por los docentes, percepciones sobre el uso de las tecnologías digitales (TD) y desafíos en la enseñanza matemática. A partir de estas tres categorías, se percibió que los principales recursos utilizados por los docentes entrevistados han sido el libro didáctico y la internet para la investigación de conceptos. Entre las principales percepciones y desafíos está la formación continuada orientada al uso de las tecnologías digitales. Sin embargo, si es necesario, repensar los recursos

\footnotetext{
${ }^{1}$ Mestre em Educação em Ciências pelo Programa de Pós-Graduação em Educação em Ciências: Química da Vida e Saúde- PPGEC; Universidade Federal do Rio Grande-FURG; Rio Grande/RS, Brasil; Email: raquelsds2013@gmail.com.

2 Doutora em Educação Ambiental pelo Programa de Pós-Graduação em Educação Ambiental - PPGEA; Universidade Federal do Rio Grande-FURG; Rio Grande/RS, Brasil; Email: tanisenovello@ furg.com.br
} 
utilizados en el aula, así como crear alternativas que atiendan las necesidades de los sujetos involucrados e inmersos en una cultura tecnológica y así contribuir a cambios significativos en el hacer docente en el escenario actual.

Palabras claves: Tecnologías Digitales; Enseñanza Matemática; Percepciones; Retos.

\begin{abstract}
With the advancement of digital technology, some educational institutions such as schools and universities have rethought their values and teaching practices. A research study was carried out with students from the Federal University of Rio Grande - FURG, a degree in Mathematics, enrolled in the discipline of Applied Technologies to Mathematics Education I. During the course one of the activities the students talked with twelve teachers of public schools, on their pedagogical practice and the presence of digital technologies in the spaces of performance and produced reports, with the aim of understanding the pedagogical accomplishment of Basic Mathematics teachers linked to the use of digital technologies. From the records generated for analysis we used the Discursive Textual Analysis (ATD) in order to understand the phenomenon investigated through the discourses produced. In this study, three categories emerged from ATD: resources used by teachers, perceptions about the use of digital technologies (TD) and challenges in teaching mathematics. From these three categories, it was noticed that the main resources used by the teachers interviewed have been the didactic book and the internet for research of concepts. Among the main perceptions and challenges is the continuing education focused on the use of digital technologies. However, it is necessary to rethink the resources used in the classroom, as well as to create alternatives that meet the needs of the subjects involved and immersed in a technological culture and thus contribute to significant changes in teaching in the current scenario.
\end{abstract}

Keywords: Digital technologies; Teach mathematics; Perceptions; Challenges.

\title{
1. Introdução
}

Considerando a evolução tecnológica presente na sociedade atual, as instituições de ensino superior, buscam através de atividades de ensino, pesquisa e extensão, formar cidadãos capazes de produzir conhecimento, transformar sua realidade e emancipar-se enquanto sujeitos envolvidos no processo de desenvolvimento humano, sejam eles no contexto científico, social, econômico, ambiental e cultural. Diante dessas mudanças, algumas universidades ainda que timidamente, estão repensando seus cursos a fim de incluírem-se no movimento pelo ensinar e aprender em uma sociedade tecnológica.

Para Kenski (2015, p.01) "uma nova cultura - cultura digital modela as formas de pensar, agir, comunicar-se com os outros, trabalhar e agir". Este novo modelo de comunicação, possibilita o desenvolvimento de novas formas de ensino e aprendizagem, mudanças de espaços de aprendizagem, relação entre alunos e professores, bem como, informações cada vez mais aceleradas e disponíveis nos diferentes dispositivos móveis, como smartphones e tabletes.

As tecnologias digitais têm influenciado na transformação dos hábitos das pessoas que diariamente realizam suas atividades através de recursos tecnológicos. No entanto, como os educadores e demais gestores estão absorvendo, aplicando e adaptando-se a era digital? Tais ações estão fazendo a diferença no fazer do profissional da educação? Estudos (MORAES, 
2012; GAUTÉRIO, RODRIGUES, 2017; CERUTTI, NORA, 2017) mostram que as Tecnologias Digitais - TD são ferramentas que podem modificar uma determinada cultura alterando as formas de atuarmos em sociedade e que precisam ser vivenciadas nos ambientes educacionais.

Para que a tecnologia contribua para o fazer pedagógico, se faz necessário compreender as potencialidades dos recursos tecnológicos, através da troca, estudo e exploração e, se permitir, transformar seu saber-ser e saber-fazer, a partir das TD, e assim modificar o ensinar e o aprender.

Nesse processo nos questionamos: Como se dá o fazer pedagógico dos professores da Educação Básica? São nativos ou imigrantes digitais? Estão inserindo as TD nas aulas? Quais são os principais desafios docentes? Desse modo, partimos de uma pesquisa desenvolvida junto com discentes da Universidade Federal do Rio Grande - FURG, do curso de Licenciatura em Matemática, matriculados na disciplina de Tecnologias Aplicada à Educação Matemática I, no qual objetiva-se compreender o fazer pedagógico dos professores de Matemática da Educação Básica.

$\mathrm{Na}$ pesquisa, os discentes conversaram com doze professores de escolas públicas, sobre o seu fazer pedagógico e a presença das TD nos espaços de atuação. Foi proposto a análise dos relatórios produzidos pelos discentes utilizando a Análise Textual Discursiva ATD (MORAES; GALIAZZI, 2007) a fim de compreender o fenômeno investigado através dos discursos que emergiram de três componentes: a unitarização, a categorização e o metatexto.

Neste estudo, das cinco categorias que emergiram elegemos três para análise: recursos utilizados pelos docentes, percepções sobre o uso das TD e desafios no ensinar Matemática. A partir do embasamento teórico de Vani Kenski (2007, 2015), Nelson Pretto (2011) e Mark Prensky (2001), entre outros, percebe-se que a maior parte dos professores que participaram da pesquisa utilizam as TD, apenas para pesquisas de determinados conceitos e procedimentos, os demais não utilizam em virtude de posicionamento contrário ao uso das TD, bem como, inúmeras limitações no planejamento e nas práticas pedagógicas.

\section{As Tecnologias Digitais no contexto educacional}

Sabe-se que as TD têm se configurado como ponto de partida para o desenvolvimento da sociedade atual, conhecida como sociedade da informação. O avanço tecnológico, isto é, o acesso à internet, aos dispositivos móveis têm apresentado inúmeros benefícios aos usuários e 
desafios para os pais, professores e demais gestores públicos, provocando grandes reflexões sobre as TD no seu fazer pedagógico e nos currículos de seus cursos, pois, não podemos negar a existência de uma cultura digital, marcada por mudanças nos modos como vivemos, nos relacionamos, obtemos informações e produzimos conhecimento. As universidades, por sua vez, estão procurando, mesmo que timidamente, modificar-se pedagogicamente a fim de fazer parte desta cultura e atender os novos acadêmicos, também chamados de nativos digitais (PRENSKY, 2001).

Uma das possibilidades de inserção das tecnologias são as redes digitais, compreendida como os espaços virtuais ou ciberespaços, isto é, a articulação entre pessoas conectadas com diferentes objetivos, no entanto, não pode ser vista como, mais um recurso a ser incorporado nas salas de aula, mas como possíveis inovações que poderão desencadear a transformação nos diferentes espaços educacionais. No entanto, as redes digitais segundo Kenski (2015), configuram-se como uma das metas do Plano Nacional de Educação (PNE) para as escolas e instituições de ensino superior que ainda esbarram na falta de recursos tecnológicos digitais, como computadores e acesso à internet, afetando diretamente no ensino e na aprendizagem.

Desta forma, o repensar as práticas pedagógicas, de forma a inserir as TD, bem como, o posicionamento pedagógico colaborativo, participativo e interativo, configuram-se como possibilidades de ensino e aprendizagem na cultura educacional atual. Nesse sentido, os professores poderão utilizar-se das TD disponíveis para ensinar determinados conceitos e procedimentos, como no ensino de Matemática, possibilitando que os estudantes aprendam através dos softwares, aplicativos e demais recursos tecnológicos. Para Mendes (2009), o uso dos softwares educativos permite ao estudante compreender e aprender os conceitos por meio da interação, visualização e da ação de fazer o que é proposto.

É nesse contexto que o presente artigo objetiva compreender como os professores de Matemática da Educação Básica estão inserindo no seu fazer pedagógico as TD e que percepções e desafios esses professores têm vivenciado ao escolherem ensinar Matemática com auxílio das TD. A análise será realizada pelo entremear dos discursos com autores que balizam o entendimento e a compreensão dos mesmos.

\section{Metodologia de produção e análise dos registros}

Ao longo da disciplina de Tecnologias Aplicada à Educação Matemática I, ofertada no segundo semestre de 2017, realizamos uma atividade em que os 28 licenciandos em Matemática produziram um relatório de observação da escola. O relatório foi produzido em 
grupos, tendo como base um roteiro construído na sala de aula no coletivo de estudantes, para guiar a conversa com os professores de Matemática. Neste roteiro haviam os questionamentos necessários para que percebêssemos o tempo de docência, qual instituição, em que espaço atua e como organiza o fazer pedagógico, se utiliza as tecnologias na sua aula, se compreende o potencial das TD no ensinar e aprender Matemática, se percebe alguma dificuldade no uso destas ferramentas, entre outros.

Dentre os onze relatórios de observação da escola, elaborados pelos grupos de discentes, percebeu-se que doze professores foram entrevistados e somente três usam as TD nas suas aulas para visualização, pesquisa e desenvolvimento de atividades na lousa digital. Notou-se que sete professores pouco utilizam as TD e quando isso acontece é para realizar pesquisas nas redes digitais e dois professores não operam as TD nas suas ações.

O método de Análise Textual Discursiva, pode ser compreendido como um processo auto organizado de construção em que novos entendimentos emergem a partir de três componentes: a unitarização, a categorização e os metatexto (MORAES; GALIAZZI, 2007). A primeira consiste na desconstrução dos textos do "corpus", a segunda consiste no estabelecimento de relações entre os elementos unitários de acordo com algumas categorias que vão emergindo e que são comuns, e a terceira é a construção de um metatexto, a partir da captação do que compreendemos por emergente e que passa a ser comunicada e validada. Tais sequencias emergem de forma recursivas de acordo com os novos entendimentos.

Neste estudo, cinco categorias emergiram das falas dos professores entrevistados as quais foram renomeadas de acordo com as comparações feitas ao longo da análise que acontece por meio da recursividade, ou seja, indo e voltando aos textos anteriores. Nesta pesquisa, será analisado as três últimas categorias, as quais intitulam-se de "Recursos utilizados pelos docentes", "Percepções sobre o uso das TD" e "Desafios no ensinar Matemática”, e apresentado os principais recursos utilizados, bem como as percepções e desafios dos docentes sobre o uso das TD a partir dos extratos retirados de cada categoria. Destaca-se que para manter em sigilo a identidade dos professores participantes serão identificados pelas letras "Pn", onde "P" se refere a professor e " $n$ " um número aleatório.

\subsection{Recursos utilizados pelos docentes}

O uso de recursos digitais para o preparo das aulas ou de determinadas atividades com os alunos tem se tornado cada vez mais comum, pois as TD estão cada vez mais inseridas no cotidiano dos estudantes, logo não temos como deixá-las fora dos espaços educacionais. Kenski (2003) ao abordar as crescentes mudanças no século XXI enfatiza que um dos grandes 
desafios da docência está em encontrar a melhor forma de utilizar a TD no processo de ensino e aprendizagem de acordo com as exigências dos novos tempos. Atualmente, existem muitas TD que podem ser pensadas e utilizadas pedagogicamente, mas para isso se faz necessário sair da zona de conforto e buscar, enquanto aprendentes digitais, formações continuadas e contínua (FREITAS, 2016) que problematizem sobre a inserção das TD na ação docente.

A instituição escolar, por sua vez, tem como atribuição informar e preparar o cidadão para os diversos temas que o auxiliem a viver em sociedade, como o uso das TD, a escola é um ambiente onde todos passam, ou que deveriam passar, um tempo da sua vida, no entanto, nem sempre os professores percebem que esta também é sua responsabilidade. Segundo os estudos de Prensky (2001) estes professores, provavelmente, nasceram em uma época em que as Tecnologias da Informação e Comunicação - TIC não eram amplamente disseminadas e não integravam sua rotina, os quais para o autor são conhecidos como imigrantes digitais.

Com isso, pode-se compreender os desafios de alguns professores em inserir nas suas práticas pedagógicas as TD, estes não percebem o quanto as TD podem contribuir para $\mathrm{o}$ ensinar e o aprender determinados procedimentos e conceitos muitas vezes abstratos como, por exemplo o ensino de Matemática. Desta forma, a escola, se configura em um espaço que pode incluir o estudante que não tem acesso às redes digitais no mundo tecnológico, desde que a mesma incorpore as TD nas atividades e assim articule o ensino escolar.

Nesse processo, uma das formas de incorporar as TD nas atividades diárias está em utilizá-las para compreensão, por exemplo, de conceitos matemáticos presentes no cotidiano do aluno. A Matemática, conhecida historicamente como uma ciência que se utiliza somente de aplicação de fórmulas, regras e resolução de algoritmos, faz parte da vida de todos e como tal precisa ser compreendida como necessária, útil e disponível no contexto dos estudantes. Além disso, a Matemática tem contribuído para o desenvolvimento de novas TD através da programação, pensamento lógico matemático e inteligência artificial, aplicações que motivam os estudantes a conhecerem e terem interesse pela Matemática.

Com o uso das TD os estudantes exploram softwares, aplicativos e demais recursos tecnológicos que simulam propriedades e comportamentos de objetos ou fenômenos, ou seja, a tecnologia auxilia na criação de modelos, representações simplificadas da realidade. No entanto, segundo Gautério e Rodrigues (2017, p. 89) “os recursos tecnológicos por si só não trarão contribuições e serão insuficientes se utilizados sem uma adequação às necessidades de cada professor em consonância com a de seus estudantes".

Além disso, para que as tecnologias ampliem as possibilidades do aprender o professor escolhe previamente quais recursos pedagógicos irá utilizar, para atender as necessidades dos 
estudantes ao ensinar determinados conceitos. Entretanto, os artefatos tecnológicos, precisam ser pensados para além de ferramentas auxiliares no processo de construção do conhecimento matemático (PRETTO, 2011), esses podem contribuir para que os estudantes adquiram, no espaço escolar, novos conhecimentos matemáticos, a partir da manipulação e simulação de softwares.

Os professores entrevistados destacaram que utilizam na maioria das vezes o livro didático, a internet e as redes sociais para o ensino de Matemática conforme a fala da professora: “(...) eu utilizo o livro didático disponível na escola” (P02), outra ressalta "(...) utilizo as redes sociais para me comunicar com meus alunos e para transmitir um fato novo ou esclarecer possíveis faltas de infraestrutura sem uma rede" (P10), e ao encontro dessa obtémse o seguinte discurso "Eu uso a internet como recurso para a busca de atividades diferenciadas" (P11).Podemos perceber que a maioria dos professores entrevistados, ao escolherem determinados recursos para o ensino de Matemática não conseguem explorar todas as potencialidades dos recursos escolhidos, ou seja, a professora ( $\mathrm{P} 10)$ ao dizer que utiliza as redes para se comunicar, acaba limitando outras potencialidades das redes sociais como o papel informativo e interativo.

As redes sociais também podem ser vistas como um ambiente de aprendizagem visto que a maioria dos estudantes tem acesso às redes sociais, desde que o docente faça deste espaço um ambiente de reflexão e construção de saberes e não fique preso a um único recurso tecnológico como o livro didático utilizado pela professora $\left(\mathrm{P}_{02}\right)$, mas que busque a atualização constante. As mídias sociais dentre elas: blogs, wikis, vídeos do You Tube, Twitter, Skype e Facebook, podem ser definidas segundo Kaplan e Haenlein (2010, p.257) como:

[...] um conjunto de aplicações baseadas na internet que [...] permitem a criação e troca de conteúdo gerado pelo usuário com base em interações entre as pessoas, em que criam, compartilham ou trocam informações e ideias em redes e comunicações virtuais.

As mídias sociais, como recurso tecnológico, estão presentes no cotidiano dos estudantes, possibilitando o diálogo, troca de informações num tempo cada vez menor, com diferentes mídias e de baixo custo. No entanto, no ambiente escolar ainda existem muitas resistências, por parte dos professores e gestores em integrar as mídias sociais à educação formal. Bates (2016, p.258), ao falar sobre as mídias sociais destaca que "seu principal valor educativo tem sido a educação não-formal, como, por exemplo, fomentar comunidades de prática online ou (...) postar tweets durante aulas ou avaliar professores”. 
Nesse sentido, as TD no ensino formal, têm sido discutidas e repensadas em diversos espaços, como por exemplo, nas formações continuadas de educadores e demais gestores das escolas, a fim de sinalizar para as potencialidades das TD mais utilizadas pelos estudantes, ampliando o conhecimento tecnológico dos professores. Os recursos tecnológicos devem ser problematizados nos diferentes espaços de formação para que os envolvidos possam conhecer e apropriar-se das TD, bem como inseri-las nas suas práticas pedagógicas com maior apropriação.

Os discursos dos professores entrevistados remetem a reflexão sobre os recursos mais utilizados pelos professores nas aulas de Matemática, bem como nos artefatos tecnológicos mais acessados pelos estudantes e que, hoje na sociedade do conhecimento, necessitam fazer parte do planejamento de aula. No entanto, os desafios enfrentados pelos educadores que escolhem trabalhar com as TD precisam ser problematizados bem como suas justificativas sobre o uso das TD.

A seguir, serão apresentadas as percepções dos professores entrevistados sobre o uso das tecnologias digitais a partir das distintas realidades vivenciadas pelos docentes.

\subsection{Percepções sobre o uso das Tecnologias Digitais}

As TD estão fortemente presentes nos diferentes espaços da sociedade atual, facilitando as atividades diárias. No contexto educacional não é diferente, hoje já existem cursos de formação continuada que podem ser realizados através do ensino presencial, ensino hibrido ou ensino a distância, todos disponíveis aos sujeitos que desejam buscam uma melhor capacitação para o trabalho docente. No entanto, em algumas escolas o que percebe-se, é um corpo docente desinteressado, desmotivado e sem perspectiva de mudança em suas práticas pedagógicas. Muitos ressaltam que uma das principais causas pelo desinteresse em práticas pautadas no uso das TD, está no fato de não conseguirem acompanhar a mudança na sociedade atual, cujas gerações estão modificam-se quase que de cinco em cinco anos.

Neste cenário, alguns professores assumem uma postura disciplinar e empirista, por possuírem pouca ou nenhuma experiência com o uso das TD, esses preferem permanecer na sua zona de conforto pedagógico do que serem conduzidos pelo que possa emergir. No entanto, é preciso enfrentar situações desfavoráveis e se aventurar na zona de risco (BORBA; PENTEADO, 2001), ou seja, se desafiar e pensar sobre o uso da TD para o ensino de Matemática. 
Nesse processo, ao perguntar sobre a importância de um ensino voltado para o uso das TD alguns professores destacam: “A Matemática em si não precisa de muitas tecnologias para o seu aprendizado, na qual as relevâncias das tecnologias acabam sendo mínimas" (P06). O professor (P08) enfatiza: "Eu não vejo tanta necessidade assim de usar as tecnologias para ensinar Matemática, eu já estou quase me aposentando, eu não tenho nem cabeça para aprender a usar as tecnologias para poder ajudar meus alunos". Outro professor destaca: "O aluno que eu tinha há 10 anos, há 5 anos, ano passado, é diferente do aluno que eu tenho hoje, então as tecnologias também têm que ser diferentes e as pessoas que estão tentando introduzir essa tecnologia tem que saber de tal realidade" $(\mathrm{P} 11)$.

Pode-se observar através dos relatos dos professores (P06) e (P08), que as TD, são desnecessárias para o ensino de Matemática. Isto se dá, pelo fato de não dominarem tais recursos e por não buscarem formação especifica para o uso de computadores e internet. No entanto, (P11) não utiliza as TD, mas reflete sobre as mudanças que estão ocorrendo na sociedade e da necessidade da escola se adequar as novas gerações de estudantes nativos digitais.

Sendo assim, o acesso à internet nas escolas de acordo com políticas públicas tem se tornado cada vez mais necessárias, bem como acesso a softwares livres. No entanto, é preciso formações continuadas que atendam os docentes através de práticas pedagógicas voltadas para os jovens e adolescentes que chegam nas escolas.

Os professores ao serem questionados sobre o que compreendem por TD destacam: "Penso ser "tecnologia" um conceito muito amplo que tem por definição qualquer aparato ou recurso facilitador de um determinado processo. No campo pedagógico, muitos recursos podem ser utilizados como "Tecnologias Educacionais", porém os que mais têm se destacado são as Tecnologias de Informação e Comunicação (TICs)" (P04).

Outro professor destaca: "Eu não entendo muito de tecnologia, não sou desse tempo, mas tecnologia para mim são todos esses avanços que vemos que nos ajudam no dia a dia" (P08). Pode-se observar que alguns professores têm utilizado as TD como recursos que auxiliam sua prática, outros por sua vez, não conseguem ver as TD como ferramentas auxiliares no processo de produção do conhecimento, logo não desenvolvem nenhuma atividade pedagógica com auxílio da TD.

O uso pedagógico das TD no ensinar Matemática através da utilização de recursos como à internet possibilita segundo Canavarro (1994) que as aulas tornem-se mais motivadoras, dinâmicas, modernizadas, facilitadoras e que gere mudanças na ação pedagógica 
e na relação entre o professor e aluno. Além disso, existem outras tecnologias digitais que podem potencializar a aprendizagem, entretanto, cabe ao docente se posicionar frente a realidade vivenciada pelos discentes emersos em uma cultura digital.

Para Pretto $(2011$, p.8) “(...) tanto a internet quanto as TD na sociedade, na escola, na educação geral, são vistas como elementos que contribuem para uma mudança radical na educação como na sociedade contemporânea", pois, o uso das TD tem facilitado e transformado a cultura de cada sujeito. A utilização das TD atrelada ao método de ensino do professor, contribui para uma melhor aprendizagem, pois, se o mesmo não estiver aberto a mudanças na sua prática docente, não conseguirá mudar a sua postura, conforme a fala do professor (P04): “(...) não faz sentido utilizar essas tecnologias sem apresentar uma metodologia diferente das que utilizamos nas nossas aulas cotidianas".

Muitos professores, como é o caso do professor (P04), tem diferentes concepções sobre o uso das tecnologias digitais, seus limites, possibilidades de uso, precisam ser estabelecidos e dialogados entre os professores e alunos de forma a não gerar confronto e sim alternativas de uso. Segundo Ribeiro (2005, p.94), “a máquina precisa do pensamento humano para se tornar auxiliar no processo de aprendizado".

Nesse sentido, para que a escola e demais espaços educacionais estejam em consonância com a crescente mudanças tecnológicas, se faz necessário que as mesmas busquem a articulação entre o conteúdo abordado, contexto do aluno e uso das TD por meio de um planejamento de aula que contemple as especificidades de cada turma. No entanto, o ensinar e aprender em uma sociedade em evolução tecnológica, torna-se um desafio, conforme será problematizado na próxima seção.

\subsection{Desafios no Ensinar Matemática}

A escola atualmente tem passado por transformações na forma como tem produzido conhecimento e essas transformações têm sido ocasionadas pela crescente evolução tecnológica. Essa por sua vez, tem ocasionado mudança de cultura, aos quais tem oportunizado maior acesso as informações através da velocidade na informação, comunicação, conforto e mobilidade. Além disso, professores e alunos tem tido maior acesso a diferentes equipamentos tecnológicos disponíveis nas suas casas e nas mãos dos professores e estudantes de todo o país através das tecnologias móveis ${ }^{3}$.

\footnotetext{
${ }^{3}$ São tecnologias feitas para movimentar-se, para que sejam levadas a qualquer lugar, utilizadas a qualquer hora e de muitas formas (MORAN,2014).
} 
Para Moran (2014, p.464) "a chegada das tecnologias móveis à sala de aula traz tensões, novas possibilidades e grandes desafios. As próprias palavras "tecnologias móveis" mostram a contradição de utilizá-la em um espaço fixo como a sala de aula". As tecnologias móveis estão cada vez mais disponíveis nas mãos dos alunos e dos professores, o que possibilita utilizar esses recursos para fins pedagógicos.

Nesse processo, os professores entrevistados ao serem questionados sobre os desafios para o desenvolvimento do seu trabalho docente, uma professora destaca: "os principais desafios na utilização das tecnologias é que a escola tem pouco recurso, minha falta de preparo, o interesse dos alunos na tecnologia e na dinâmica de aula é que eu acredito que ajude a tornar a aula diferente e mais envolvente" (P02). Outra professora ressalta "(...) sempre que procuro usar as tecnologias esbarro na falta de manutenção dos equipamentos e isso inviabiliza ainda mais uma aula nesses moldes" (P10). Outro educador menciona: “( ...) a internet é escassa, não houve também preparação dos professores, o que resultou no pouco uso dos equipamentos" (P11).

Podemos perceber através dessas falas que um dos desafios é a falta de infraestrutura apropriada para o desenvolvimento das atividades e também a formação de educadores para lidar com as tecnologias digitais. De acordo com a pesquisa TIC Educação 2013 desenvolvida nas escolas públicas de todo o Brasil, houve um aumento de (71\%) de escolas com acesso WI-FI. No entanto, a conexão ainda é um desafio, especialmente se considerada a necessidade de uso simultâneo de equipamentos em uma mesma escola.

Tais informações, vão ao encontro da realidade dos professores entrevistados, visto que não adianta ter acesso à internet se a conexão é baixa, ou ter computadores que não funcionam por falta de equipamentos. Uma professora aponta: “(...) foi bem difícil o desenvolvimento da atividade, por que, as turmas eram grandes, e são poucos computadores, então eram dois ou três alunos por computador" (P08). Segundo a pesquisa ${ }^{4}$ TIC Educação 2013 “O número médio de computadores de mesa em funcionamento é de 19,1 para um número médio de 653 alunos por escola, o que pode ser considerado uma limitação para o uso pedagógico das TD” (VIANA, 2016, p.465).

Muitos professores acabam desistindo de desenvolver uma aula com o auxílio do computador e da internet pela falta de recursos, outros passam a utilizar as tecnologias móveis, ou seja, preferem levar seu notebook do que depender dos computadores da escola.

\footnotetext{
${ }^{4}$ A pesquisa é realizada pelo Centro Regional de Estudos para o Desenvolvimento da Sociedade da Informação (CETIC).
} 
Além disso, em muitas escolas os professores estão utilizando os smartphones para o desenvolvimento da aula. Os resultados da pesquisa TIC Educação 2013, relacionados a infraestrutura indicam, aumento da tendência de uso de dispositivos móveis como ferramenta para a educação formal. Outro desafio mencionado pelos professores entrevistados está na falta de formação específica para o uso das TD com fins pedagógicos, conforme a fala da professora (P08): “(...) no dia eu estava nervosa, mas os próprios alunos me ajudaram onde eu não sabia mexer". Esta professora, se sentiu nervosa por não dominar o recurso tecnológico escolhido, mas uma das potencialidades do uso das TD está em oportunizar a interação e a troca de experiências entre os envolvidos o que torna a aula prazerosa

Outro professor destaca: "Tenho grande dificuldade em adequar os conteúdos de Matemática que ensino às tecnologias" (...) parto em busca de uma formação que me prepare mais nesse sentido, especialização e mestrado, mas, para minha frustração, continuo sem saber como aplicar os conteúdos de Matemática utilizando as tecnologias" (P04). Compreendemos que, não basta realizar um único curso de formação de educadores, visto que a cada dia novas formas de ensino e aprendizagem surgem de pesquisas desenvolvidas com novos educadores e estudantes.

Segundo Gatti (2010, p.01 e 02) "a formação de professores tem sido um dos grandes desafios para as políticas educacionais, [...] no ensino superior do Brasil não tivemos até aqui iniciativa nacional forte o suficiente para adequar o currículo às demandas do ensino”. Neste contexto, os temas formação nas licenciaturas, bem como formação continuada precisam estar entre as prioridades nas discussões sobre o currículo e práticas de inserção dos licenciandos no contexto escolar, a fim de que esses tenham uma maior clareza sobre os desafios que irão enfrentar.

Um professor menciona: “(...) não sobra muito tempo para estudar um pouco mais a fundo para achar meios de trabalhar com os alunos, sinto um pouco de falta de cursos que ajudam a como aplicar as tecnologias" (P11). Através desta fala, podemos observar duas limitações: a falta de tempo para o planejamento de aula e a falta de formação continuada que deverão ser repensadas entre os próprios professores e gestores a fim de desenvolverem, como Gatti (2010, p. 01) aponta “(...) ações agressivas na área educacional cuidando, sobretudo, dos formadores, (...) da disseminação do conhecimento e de elementos substanciais da cultura". Dentre essas ações está o próprio tempo para o planejamento de aulas direcionadas à cultura dos discentes e uso das TD. 
As TD estão cada vez mais disponíveis a todos, mas o uso pedagógico da internet depende exclusivamente da criatividade docente, da pesquisa sobre novas formas de ensino e adaptação a realidade dos estudantes o que exigirá

[...] planejamento, investigação, adequação dos espaços e tempos a realidade dos alunos e dos conteúdos que se pretende ensinar. Requer tempo, dedicação, avaliação constante, cooperação e muita comunicação entre todos os envolvidos, É preciso vontade política dos dirigentes de todos os níveis para garantir a viabilização dos projetos educacionais flexíveis e inovadores. (KENSKI, 2015, p.13)

Por último, a professora (P11) ressalta: “(...) sinto um pouco de falta de cursos que ajudam a como aplicar as tecnologias". No entanto, não é o que os cursos objetivam para um professor em formação continuada, ou seja, que apenas reproduza as atividades abordadas no curso, mas que a partir do que foi discutido nos cursos possa adaptar e ampliar as propostas de atividade a sua realidade.

Ademais, o relato dos professores aponta alguns desafios no ensinar Matemática a partir das TD na escola, desde a infraestrutura escolar, formações continuadas direcionada a realidade escolar até políticas públicas educacionais. O processo de ensino de Matemática na atualidade tem cada vez mais exigido, envolvimento, dedicação e planejamento, a fim de que haja uma maior produção e transformação do conhecimento.

\section{Considerações Finais}

Com base neste estudo, o qual objetivou compreender como os professores de Matemática da Educação Básica estão inserindo no seu fazer pedagógico as TD e que percepções e desafios esses professores têm vivenciado ao escolherem ensinar Matemática com auxílio das TD percebeu-se, a partir dos extratos dos professores que participaram da conversa com os licenciandos, a necessidade de repensar os recursos utilizados em sala de aula de forma a atender os nativos digitais, pois a escolha desses recursos deverá contemplar a cultura desses estudantes. Refletir sobre os modos como os estudantes estão, comunicando, relacionando e interagindo, tem fundamental importância para a aprendizagem dos mesmos principalmente por estarem imersos em uma cultura digital voltada para o uso de recursos digitais.

Também, a necessidade de problematizar nos espaços educacionais sobre os cursos de formação continuada voltados para o uso das TD e tempo para planejamento de aula nesse contexto, para os docentes, tem sido um dos desafios da educação atual. No entanto, o que se necessita, a partir das principais necessidades apresentadas ao longo das falas dos professores, 
é criar condições concretas e favoráveis que atendam as demandas de cada comunidade, bem como, dos discentes e docentes.

Para isso, das três categorias discutidas, a primeira intitulada "Recursos utilizados pelos docentes", mostrou os recursos utilizados por todos os professores entrevistados, dentre eles o livro didático, a internet, redes sociais e softwares. A segunda categoria intitulada "Percepções sobre o uso das tecnologias digitais", consta as falas dos professores que não utilizam as TD. Alguns professores compreendem as TD como recursos desnecessários para aprendizagem dos estudantes, outros não compreendem e não sabem utilizar as TD e por estarem próximos ao período de aposentadoria, preferem seguir com o mesmo método de ensino e com os mesmos recursos. A terceira categoria intitulada "Desafios no ensinar Matemática" apresenta alguns desafios como a infraestrutura escolar, falta de computadores disponíveis, baixo acesso sem fio, pouco incentivo escolar, no que se refere a cursos de formação continuada e pouco tempo para planejamento de aula com auxílio das TD.

Percebe-se que dos professores que participaram da conversa com os licenciandos, a maioria utiliza as TD para pesquisa de determinados conceitos nas redes digitais. Compreende-se que está ação é ocasionada pela falta de conhecimento sobre o potencial das TD na e para a educação, não se permitindo utilizar-se de forma pedagógica. Os demais professores que não utilizam ou pouco utilizam, justificam suas escolhas por não possuírem formação continuada para uso do computador e internet, por não terem uma infraestrutura adequada ao trabalho docente e por não terem tempo para o planejamento de aula com recursos tecnológicos.

No entanto, frente a situação vivenciada por muitos professores e gestores da educação básica e ensino superior, refletir e criar alternativas frente ao avanço das TD configura-se como um caminho alternativo para mudanças educacionais direcionadas e focadas à realidade dos discentes. Hoje saber utilizar o computador e a internet é o mínimo, para o docente que deseja ensinar crianças e jovens imersos em uma cultura digital. Dessa forma, é importante refletir, bem como entender o posicionamento de alguns professores que preferem seguir as mesmas práticas de ensino de décadas atrás do que utilizar as TD como ferramentas potencializadoras do ensino e da aprendizagem.

Assim, o uso pedagógico das TD precisa ser discutido constantemente nos espaços escolares e nas instituições de ensino superior, que formam profissionais da educação, para que uma nova cultura se constitua, permeada por mudanças na forma de ensinar e de agir enquanto sujeitos. Além disso, olhar e ver as possibilidades de ensino através das TD, ou seja, criar uma cultura de aprender através dos diferentes espaços, não limitando-o somente a sala 
de aula enquanto espaço físico, mas pensar em alternativas, pois atualmente, manter uma sala de aula com acesso à internet ou computadores conectados à internet, bem como demais recursos necessários para o ambiente educacional, tem-se tornado cada vez mais difícil diante das políticas educacionais.

Logo, é a partir das questões, desafios e percepções levantadas neste estudo, pelos professores de Matemática buscar-se-á nos diferentes contextos, potencializar o ensinar e o aprender nos tempos atuais.

\section{Referências}

ABREU, M. D. P. A Laboratório de Matemática: um espaço para a formação continuada do professor- Dissertação (Mestrado) - Universidade Federal de Santa Maria, Rio Grande do Sul, 1997.

BATES, T. Educar na era digital: design, ensino e aprendizagem. São Paulo: Artesanato Educacional, 2016. ISBN 9788564803060.

BORBA, M. C; PENTEADO, M. G. Informática e educação matemática. Belo Horizonte: Autêntica, 2001. 98p. ISBN 9788575260210.

CANAVARRO, A. P. Concepções e práticas de professores de matemática: três estudos de casos.1993. 361f. Dissertação (Mestrado em Educação) - Departamento de Educação da Faculdade de Ciências, Universidade de Lisboa, Lisboa, 1994.

CERUTTI, E; NORA, M. D. Reflexões sobre a Cibercultura no ensino superior: um olhar sobre os cursos de licenciatura. Conhecimento \& Diversidade, Niterói, v. 9, n. 18, p. 32-46, jul./set. $2017 . \quad$ Disponível em: https://revistas.unilasalle.edu.br/index.php/conhecimento_diversidade/article/viewFile/4099/p df. Acesso em: 2 out. 2019.

FREITAS, L. S. De imigrante à aprendente digital: A formação de um e-professor. Dissertação de Mestrado. Universidade Federal do Rio Grande. Programa de Pós - Graduação em Educação em Ciências: química da vida e saúde, Rio Grande RS, 2016.

GATTI, B. A. Formação de professores no Brasil: características e problemas. Educação \& Sociedade, v. 31, n. 113, 2010. ISBN 8585701471.

GAUTÉRIO, V. L. B; RODRIGUES, S. C. O aprender em ambientes de aprendizagem: Configurando uma cultura escolar. 1. ed. Deutschland: Novas Edições Acadêmicas, 2017. v.1.

KAPLAN, A. HAENLEIN, M. Users of the word, unite! The challenges and opportunities of social media, Business Horizons, Vol. 53, Nº1, pp. 59-68, 2010. In. BATES, T. Educar na era digital: design, ensino e aprendizagem. São Paulo: Artesanato Educacional, 2016. ISBN 9788564803060 .

KENSKI, V. M. Tecnologias e Ensino Presencial e a Distância. Campinas, SP: Papirus, 2003. 144 p. ISBN 8530807081. 
KENSKI, V. M. Educação e Tecnologias: O novo ritmo da informação. Campinas, SP: Papirus, 2007.ISBN 9788530808280.

KENSKI, V. M. Educação e Internet no Brasil. ResearchGate. University of São Paulo.Disponível

em https://www.researchgate.net/publication/281121751_Educacao_e_Internet_no_Brasil.

Acesso em: 24 de mai. 2019.

MENDES, I. A. Matemática e investigação em sala de aula. Tecendo redes cognitivas na aprendizagem. São Paulo: Livraria da Física, 2009.ISBN 9788578610180.

MORAES, M. C. O paradigma educacional emergente. Campinas: Papirus, 2012. ISBN 8530804783.

MORAES, R; GALIAZZI, M. C. Análise textual discursiva. Ijuí: Unijuí, 2007.ISBN 9788574296098 .

MORAN, J. M; MASETTO, M; BEHRENS, M. A. Novas tecnologias e mediação pedagógica. Campinas, SP: Papirus, 2014. ISBN 8530805941.

PRENSKY, M. Digital natives, Digital Immigrants. On the Horizon. Vol. 9, Nº.5, 2001.ISSN 10748121.

PRETTO, N. L. O desafio de educar na era digital: educações. Revista Portuguesa de Educação, Minho, v.24, n. 1, 2011. p. 95 -118.

RAMAL, A. C. Histórias de gente que ensina e aprende. Bauru, SP: EDUSC, 1999.ISBN 8586259802.

RIBEIRO, O. J. Educação e novas tecnologias: um olhar para além da técnica. In: COSCARELLI, C. V. RIBEIRO, A. E. (Org.). Letramento digital: aspectos sociais e possibilidades pedagógicas. $3^{\circ}$ ed. Belo Horizonte: Ceale: Autêntica, 2005. p.86 -97.ISBN 85-7526-170-3.

VIANA, M. Sou Educador: ensino fundamental II.1.ed.- São Paulo: Eureka, 2016. ISBN 9788555671517. 